\title{
The Study of Ultrasonic Degradation of Superabsorbent Hydrogels
}

\author{
Rajabali Ebrahimi, Giti Tarhande, and Saeed Rafiei \\ Chemistry Department, Science Faculty, Islamic Azad University, Takestan Branch, Takestan, Iran \\ Correspondence should be addressed to Rajabali Ebrahimi, pr_ebrahimi_r@yahoo.com \\ Received 11 July 2012; Revised 20 September 2012; Accepted 25 September 2012 \\ Academic Editor: Robert Engel
}

Copyright ( $) 2012$ Rajabali Ebrahimi et al. This is an open access article distributed under the Creative Commons Attribution License, which permits unrestricted use, distribution, and reproduction in any medium, provided the original work is properly cited.

\begin{abstract}
Viscometry is a valid and practical approach for monitoring the degradation of polymers in solution. In this work, at constant power and pulse, the effects of different operating parameters such as time of irradiation, temperature, solution concentration, volume, solvent, and immersion depth of horn on the rate of degradation have been investigated in aqueous solution using laboratory scale operation. A method of viscometry was used to study the degradation behavior of aqueous dispersions of microgels. The experimental results show that the viscosity of polymer solution decreased with an increase in the ultrasonic irradiation time and approached a limiting value. The present work has enabled us to understand the role of the different operating parameters in deciding the extent of viscosity reduction in aqueous dispersions of microgels and also the controlling effects of them.
\end{abstract}

\section{Introduction}

Hydrogels, both natural and synthetic, are used in a myriad of applications, particularly as medical devices, including therapeutic contact lenses, wound dressings, injectable drugdelivery vehicles, and tissue-regeneration scaffolds. Biomaterials need to be removed from the body once they complete their roles in the body, and degradable materials could be ideal for this purpose [1-5]. In addition, drug molecules may be covalently bound to nondegradable polymer networks with a degradable linkage. As such, the rate of release for these gels is dependent on the cleavage kinetics of the drugnetwork linkage. Shortening of the polymer chains can be achieved by various methods such as thermal, photo, and catalytic degradation [6-8]. The methods like UV [9-13], gamma radiation $[13,14]$, and microwave $[14,15]$ are also important. Ultrasound, photo, and chemical methods require less energy for polymer degradation. Further, interaction between them and the polymeric systems can help find the degradation pathways or mechanisms [8-10, 16-18].

Many scientists have investigated the ultrasound degradation of polymers $[7,10,12-14]$. The effects of various parameters like ultrasound pulse and intensity $[12,17-20]$, frequency $[20,21]$, temperature $[17,22-24]$, vapor pressure, volume [19, 23, 24], solvent [17, 22], dissolved gases [21], molecular weight $[25,26]$, and polymer concentration $[12$, $19,20]$ on the ultrasonic degradation of macromolecules have been studied. The ultrasonic degradation of low density polyethylene at different concentrations, volumes, and temperatures has been studied. The results showed that the extent of degradation decreased with an increase in reaction volume and concentration. Also, it has been observed that the rate of degradation increases as the concentration of polymer solution is decreases. Since at high concentrations, entanglements influence the energy transfer processes between solvent and polymer and appear to reduce the probability of degradation. The degradation of aqueous polyvinyl alcohol at $25^{\circ} \mathrm{C}$ has been investigated, and results showed that the degradation rate of PVA solution increases with decreasing of solution concentration. The increase in rate constant is attributed to the fact that at lower concentration and volume, the intensity of cavitation phenomenon is increased, and the extent of chain breaking increases.

Acrylic acid (AA) and acrylamide (AAm) are two watersoluble important monomers in industry that the research 
work on their polymers and gels, and some other hydrogels in solution mainly focused on the following categories.

(i) Synthesis and gelation, without ultrasound [3] and in the presence of ultrasound;

(ii) degradation, without ultrasound [4] and in the presence of ultrasound $[10,12,13,17,27]$;

(iii) swelling and degradation, without ultrasound and in the presence of ultrasound [11].

In our previous work, we investigated the effects of sonication parameters and showed that the rate of degradation increases with increasing ultrasonic power and pulse. The present work investigates and optimizes different operating parameters on the hydrogels ultrasonic degradation using laboratory scale. The extent of degradation has been quantified in terms of the change in the intrinsic viscosity of the solution, which is a simple method for monitoring the rate of degradation of these systems. The purpose of this study is to present the effect of temperature, concentration, volume, solvent, depth of the horn, and some other parameters on degradation of these hydrogels in water. The ultrasonic process has been confirmed to be applicable for many kinds of hydrogels and gels.

\section{Experiments}

2.1. Materials, Hydrogel Formation, and Swelling Measurements. The monomer, acrylic acid (AA, Merck), was used after vacuum distillation. Acrylamide (AAm), ammonium persulfate (APs), and methylene bisacrylamide (MBAAm) were of laboratory reagent grade and were obtained from Fluka. All solutions were prepared using distilled and deionized water. The hydrogel was prepared according to our earlier works in optimum conditions [25]. After grinding, the powdered superabsorbent hydrogel was stored away from moisture, heat, and light. The equilibrium swelling was calculated using the following equation (1) [9]:

$$
\text { water absorbance }=\frac{\left(W_{S}-W_{D}\right)}{W_{D}},
$$

where $W_{S}$ and $W_{D}$ are the weights of the swollen gel and the dry sample, respectively. So, absorbency was calculated as grams of water per gram of dry hydrogel $(\mathrm{g} / \mathrm{g})$.

2.2. Hydrogel Degradation and Viscosity Measurements. The reaction was carried out in a $20-\mathrm{mL}$ stainless steel cylinder, and distilled water was used as solvent. 12-mL hydrogel sample (containing $0.1 \mathrm{~g}$ gel) was taken each time, and the cylinder was held in a constant temperature $\left(25^{\circ} \mathrm{C}\right)$ circulator water bath $\left( \pm 0.1^{\circ} \mathrm{C}\right)$. Ultrasound was coupled directly to the reaction system by a horn type homogenizer (Sonopuls HD 2070, Bandelin) with HF power of $70 \mathrm{~W}$ and frequency of $20 \mathrm{KHz}$. The diameter of the horn tip was $2 \mathrm{~mm}$. The probe was immersed $20 \mathrm{~mm}$ below the liquid surface (center of the solution). The cylinder was put in a sound proof box with clear acrylic glass door. Periodically, samples of sonicated solutions were removed for viscosity measurements using

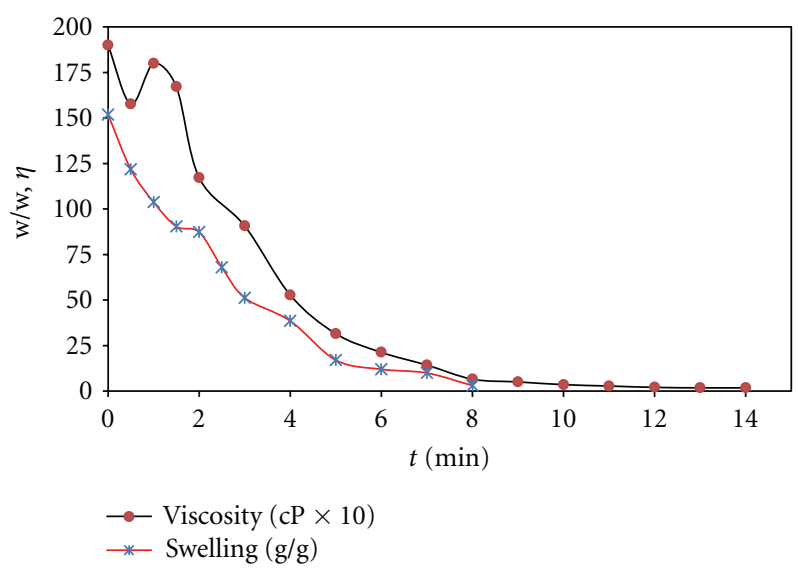

FIGURE 1: Typical changes in viscosity and swelling of the hydrogel solution as a function of time in $25^{\circ} \mathrm{C}$.

a rotational viscometer (DV-II + Pro RV, Brookfield). The viscometer had a small sample adapter with a cylindrical spindle type (number 62) and was rotated at $100 \mathrm{rpm}$. The result was a direct reading of the viscosity value in $\mathrm{cP}$ between 0 and 2300. Experiments have been repeated at least twice to check the reproducibility of the obtained data for the variation of viscosity against time for all cases.

\section{Results and Discussion}

3.1. Variation of Viscosity and the Swelling of Hydrogel with Sonication Time. The ultrasonic degradation is a fluid mechanical process; thus, viscosity of the solvent plays an important role in determining the degradation rate. The effect of sonication time on the intrinsic viscosity of the aqueous dispersions of microgels has been investigated at 12$\mathrm{mL}$ reaction volume, depth of horn as $2 \mathrm{~cm}$, and operating temperature at $25^{\circ} \mathrm{C}$. Figure 1 shows the effect of sonication time on the viscosity and swelling of hydrogel sample. It can be seen from the figure that with the use of sonication, viscosity decreased significantly for the hydrogel. Below the limiting viscosity, the polymer chain was so short that it followed ultrasonic vibrations flexibly, and cleavage at the center of the molecule did not take place anymore [19-21]. The best compromise between the duration of sonication and the reduction of the molar mass is found after $12 \mathrm{~min}$.

According to the Figure 1, the swelling is decreased by passing the time from 0 up to 8 min smoothly. The maximum absorbency $(152 \mathrm{~g} / \mathrm{g})$ is in beginning. Similar variations were observed in degradation behavior of dextran hydrogels composed of positively and negatively charged microspheres [28].

3.2. Effect of Temperature on the Rate of Degradation. The effect of temperature on the degradation of hydrogel was studied; the variation of $\eta$ with sonication time at different temperatures is illustrated in Figure 2. The results indicate that the cavitation effects at lower temperature were more effective than the mechanical effects at higher temperature in the viscosity depression of hydrogel solutions. At higher 


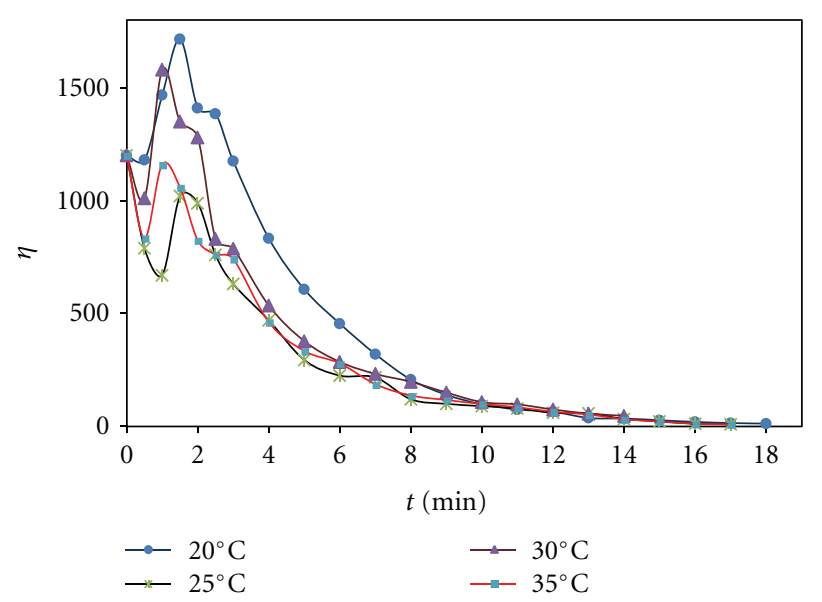

FIGURE 2: Effect of temperature on sonochemical degradation of hydrogel.

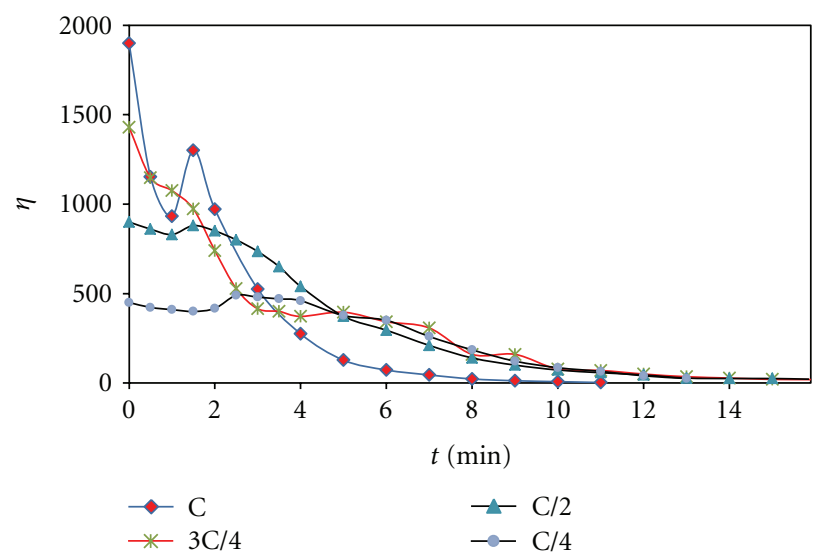

FIGURE 3: Effect of concentration of hydrogel on the extent of viscosity reduction.

temperature, clearly the vapor pressure will be higher and so the vapor will enter the cavitation bubble, which leads to the cushioning effect $[19,22]$. The increased viscosity of the solvent at lower temperatures increases rapid transmission of shock waves and favors the defragmentation of polymer chain at low strain rates [22].

3.3. Effect of Concentration of Hydrogel. Effect of concentration was investigated at a constant reaction volume of $12 \mathrm{~mL}$ for different concentrations of $\mathrm{C}, 3 \mathrm{C} / 4, \mathrm{C} / 2$, and $\mathrm{C} / 4$, respectively, and the obtained results have been given in Figure 3. Under the same conditions, the decrease in $\eta$ of the sample with a high concentration is more than of the sample with a low concentration. These results indicate that the extent of degradation is more pronounced in more concentrated solutions. An increase in viscosity with concentration results in the molecules becomes more mobile in solution, and the velocity gradients around the collapsing bubbles therefore become larger, resulting in more extents of viscosity reduction. Indeed there are more molecules to be

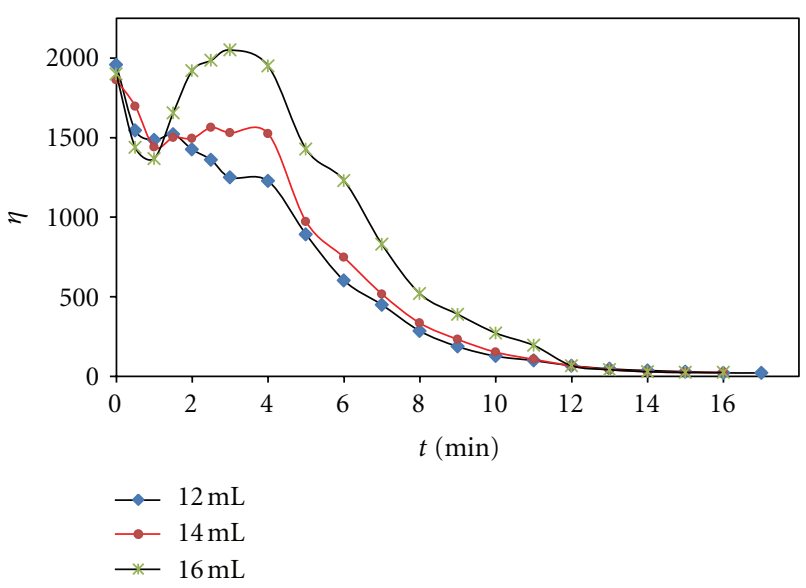

FIGURE 4: Effect of volume on viscosity changes and related degradation rate constant $(k)$.

degraded when the concentration is higher and that is why the degradation is faster.

3.4. Effect of Volume on the Rate of Degradation. The observed dependence of the efficiency of ultrasonic depolymerization on the volume of the sonicated sample can be explained by the fact that the most efficient depolymerization occurs in the proximity of the inserted probe, since the energy of the ultrasonic waves decreases with increasing distance from the probe. Therefore, the best yields of ultrasonication were obtained for the equipment used in the small volumes of solution. Indeed with an increase in the operating volume, the nonuniformity of the cavitational activity increases (more dead zones where the cavitational activity is minimal) resulting into detrimental effects. Figure 4 shows the effect of reaction volume on the limiting viscosity of hydrogel solution when it is subjected to ultrasonic degradation. It shows that the limiting viscosities for hydrogel solution at 12,14 , and $16 \mathrm{~mL}$ reaction volume is nearly equal, but for $16 \mathrm{~mL}$ sample has a delay.

3.5. Effect of Solvent on the Rate of Degradation. The effect of solvent on the ultrasonic degradation was studied by investigating the degradation of hydrogel at $30^{\circ} \mathrm{C}$ using different ethanol/water ratio as solvent, and Figure 5 depicts the results. The variation in rate coefficient for different solvents is mainly attributed to their cavitation capacity which governs the intensity of shock waves radiated from the collapsing cavity. The degradation rate in a particular solvent mainly depends upon the properties of solvent like vapor pressure and kinematic viscosity which primarily affect the cavitation capacity of the solvent. It was observed that the rate is maximum for pure water (ETOH 0\%).

3.6. Effect of Depth of Horn on the Rate of Degradation. The extent of mixing in the reactor is dependent on the immersion depth of the horn tip. The observed results can be attributed to the fact that flow pattern of liquid in terms of direct circulation currents generated due to the 


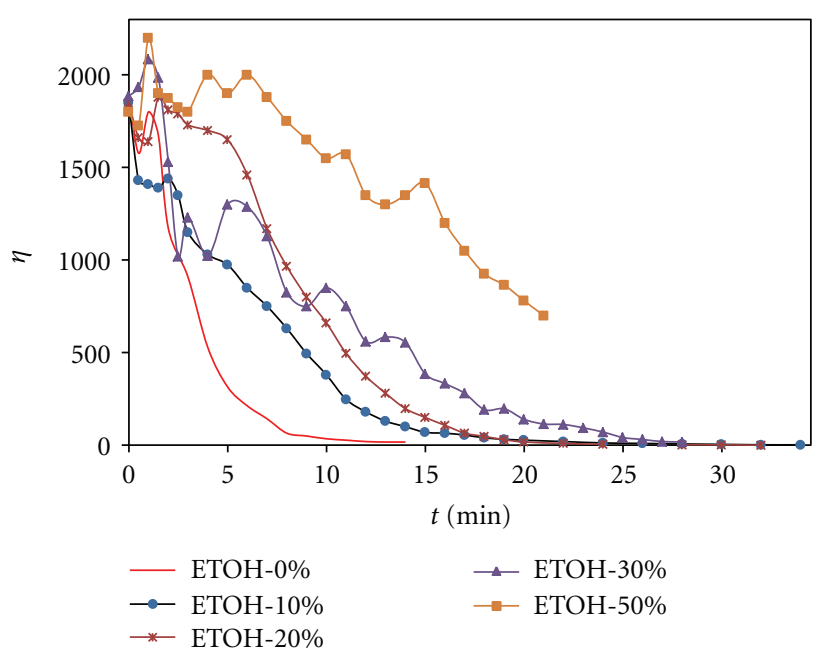

FIGURE 5: Effect of solvent on the extent of viscosity reduction of hydrogel solution.

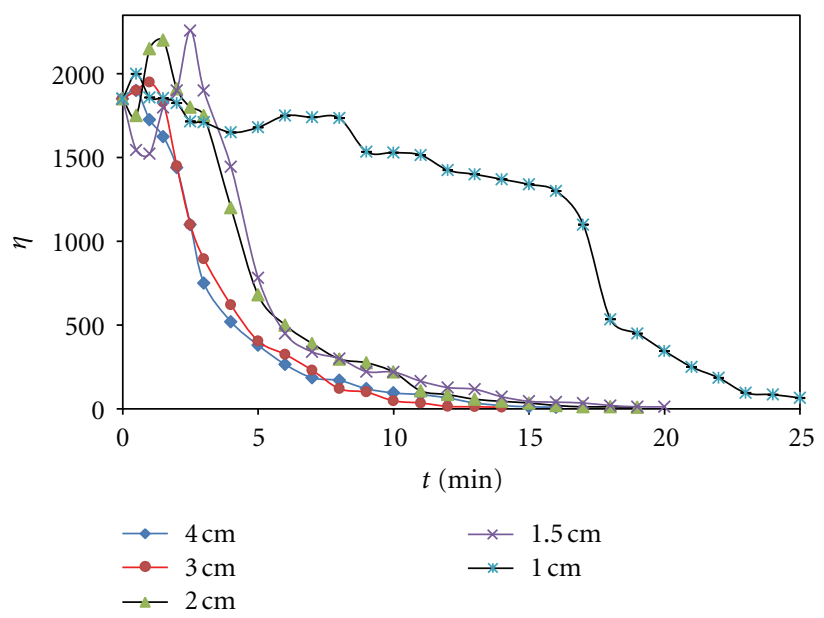

Figure 6: Effect of depth of horn on the extent of viscosity reduction of hydrogel solution.

acoustic streaming and reflections from the bottom of the reactor depends on the distance of horn tip immersed in the solution. Figure 6 shows the effect of depth of horn on the viscosity reduction for samples of hydrogel at constant volume of $12 \mathrm{~mL}$. It has been observed that, during the initial stages of operation, the extent of viscosity reduction is higher for the operation with depth as 3 and $4 \mathrm{~cm}$. However, the final extent of reduction in intrinsic viscosity is marginally higher at a depth of $3 \mathrm{~cm}$. The least effect is related to $1 \mathrm{~cm}$ depth.

\section{Conclusions}

Viscometry is a valid and practical approach for monitoring the degradation of polymers in solution. The present research shows that the power ultrasound can marginally reduce the viscosity of the hydrogel solutions below $10 \mathrm{mPa} s$ after $20 \mathrm{~min}$ at $25^{\circ} \mathrm{C}$. A commercially important hydrogel based on acrylic acid and acrylamide was investigated, and the ultrasonic process can be developed to other kinds of hydrogels. The effect of solvent and temperature on the ultrasonic degradation of hydrogel was studied, and it was mainly attributed to vapor pressure of the solvent, and the variations of the rate with temperature, vapor pressure, and kinematic viscosity were analyzed. The effect of vapor pressure on the ultrasonic degradation is very high compared to viscosity.

\section{Acknowledgment}

The authors would like to thank the Islamic Azad University for providing financial support for this work.

\section{References}

[1] K. Y. Lee, K. H. Bouhadir, and D. J. Mooney, "Controlled degradation of hydrogels using multi-functional cross-linking molecules," Biomaterials, vol. 25, no. 13, pp. 2461-2466, 2004.

[2] G. J. Price, "The use of ultrasound for the controlled degradation of polymer solutions," in Advances in Sonochem, Jai Press, 1990.

[3] X. Li and Y. Cui, "Ultraviolet-Induced decomposition of acrylic acid-based superabsorbent hydrogels crosslinked with N,N-methylenebisacrylamide," Journal of Applied Polymer Science, vol. 108, no. 6, pp. 3435-3441, 2008.

[4] R. Vinu and G. Madras, "Kinetics of sono-photooxidative degradation of poly(alkyl methacrylate)s," Ultrasonics Sonochemistry, vol. 18, no. 2, pp. 608-616, 2011.

[5] D. Mawad, P. J. Martens, R. A. Odell, and L. A. Poole-Warren, "The effect of redox polymerisation on degradation and cell responses to poly (vinyl alcohol) hydrogels," Biomaterials, vol. 28, no. 6, pp. 947-955, 2007.

[6] M. T. Taghizadeh and R. Abdollahi, "Sonolytic, sonocatalytic and sonophotocatalytic degradation of chitosan in the presence of $\mathrm{TiO}_{2}$ nanoparticles," Ultrasonics Sonochemistry, vol. 18, no. 1, pp. 149-157, 2011.

[7] N. Daraboina and G. Madras, "Kinetics of the ultrasonic degradation of poly (alkyl methacrylates)," Ultrasonics Sonochemistry, vol. 16, no. 2, pp. 273-279, 2009.

[8] U. D. Harkal, P. R. Gogate, A. B. Pandit, and M. A. Shenoy, "Ultrasonic degradation of poly(vinyl alcohol) in aqueous solution," Ultrasonics Sonochemistry, vol. 13, no. 5, pp. 423428, 2006.

[9] B. David, "Sonochemical degradation of PAH in aqueous solution-part I: monocomponent PAH solution," Ultrasonics Sonochemistry, vol. 16, no. 2, pp. 260-265, 2009.

[10] V. K. Konaganti and G. Madras, "Ultrasonic degradation of poly(methyl methacrylate-co-alkyl acrylate) copolymers," Ultrasonics Sonochemistry, vol. 17, no. 2, pp. 403-408, 2010.

[11] A. C. Petit, N. Noiret, J. Guezennec, N. Gondrexon, and S. Colliec-Jouault, "Ultrasonic depolymerization of an exopolysaccharide produced by a bacterium isolated from a deep-sea hydrothermal vent polychaete annelid," Ultrasonics Sonochemistry, vol. 14, no. 2, pp. 107-112, 2007.

[12] M. T. Taghizadeh and T. Asadpour, "Effect of molecular weight on the ultrasonic degradation of poly(vinyl-pyrrolidone)," Ultrasonics Sonochemistry, vol. 16, no. 2, pp. 280-286, 2009.

[13] G. Antti, P. Pentti, and K. Hanna, "Ultrasonic degradation of aqueous carboxymethylcellulose: effect of viscosity, molecular mass, and concentration," Ultrasonics Sonochemistry, vol. 15, no. 4, pp. 644-648, 2008. 
[14] M. T. Taghizadeh and A. Bahadori, "Degradation kinetics of poly (vinyl-pyrrolidone) under ultrasonic irradiation," Journal of Polymer Research, vol. 16, no. 5, pp. 545-554, 2009.

[15] N. B. Shukla, N. Darabonia, and G. Madras, "Ultrasonic degradation of poly (acrylic acid)," Journal of Applied Polymer Science, vol. 112, no. 2, pp. 991-997, 2009.

[16] A. V. Mohod and P. R. Gogate, "Ultrasonic degradation of polymers: effect of operating parameters and intensification using additives for carboxymethyl cellulose (CMC) and polyvinyl alcohol (PVA)," Ultrasonics Sonochemistry, vol. 18, no. 3, pp. 727-734, 2011.

[17] V. Desai, M. A. Shenoy, and P. R. Gogate, "Degradation of polypropylene using ultrasound-induced acoustic cavitation," Chemical Engineering Journal, vol. 140, no. 1-3, pp. 483-487, 2008.

[18] T. J. Mason, Sonochemistry, Oxford Press, 1999.

[19] J. Xie, X. Liu, and J. Liang, "Absorbency and adsorption of poly(acrylic acid-co-acrylamide) hydrogel," Journal of Applied Polymer Science, vol. 106, no. 3, pp. 1606-1613, 2007.

[20] E. Turan and T. Caykara, "Swelling and network parameters of pH-sensitive poly (acrylamide-co-acrylic acid) hydrogels," Journal of Applied Polymer Science, vol. 106, no. 3, pp. 20002007.

[21] R. París and I. Quijada-Garrido, "Swelling behaviour of thermo-sensitive hydrogels based on oligo(ethylene glycol) methacrylates," European Polymer Journal, vol. 45, no. 12, pp. 3418-3425, 2009.

[22] P. Cass, W. Knower, E. Pereeia, N. P. Holmes, and T. Hughes, "Preparation of hydrogels via ultrasonic polymerization," Ultrasonics Sonochemistry, vol. 17, no. 2, pp. 326-332, 2010.

[23] X. Wang, J. A. Kluge, G. G. Leisk, and D. L. Kaplan, "Sonication-induced gelation of silk fibroin for cell encapsulation," Biomaterials, vol. 29, no. 8, pp. 1054-1064, 2008.

[24] A. S. Sarvestani, W. Xu, X. He, and E. Jabbari, "Gelation and degradation characteristics of in situ photo-crosslinked poly(1lactide-co-ethylene oxide-co-fumarate) hydrogels," Polymer, vol. 48, no. 24, pp. 7113-7120, 2007.

[25] R. Ebrahimi, "Influence of ultrasonic parameters on degradation of acrylic acid/acrylamide copolymer based superabsorbent hydrogels cross-linked with NMBA," Iranian Polymer Journal, vol. 20, pp. 11-20, 2012.

[26] V. S. Sutkar and P. R. Gogate, "Mapping of cavitational activity in high frequency sonochemical reactor," Chemical Engineering Journal, vol. 158, no. 2, pp. 296-304, 2010.

[27] J. Park and D. Kim, "Effect of polymer solution concentration on the swelling and mechanical properties of glycol chitosan superporous hydrogels," Journal of Applied Polymer Science, vol. 115, no. 6, pp. 3434-3441, 2010.

[28] S. R. Van Tomme, C. F. van Nostrum, S. C. de Smedt, and W. E. Hennink, "Degradation behavior of dextran hydrogels composed of positively and negatively charged microspheres," Biomaterials, vol. 27, no. 22, pp. 4141-4148, 2006. 


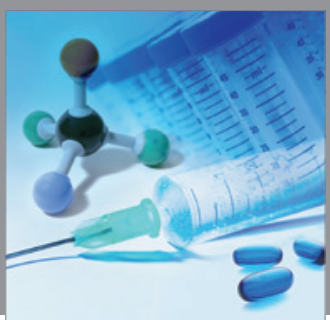

International Journal of

Medicinal Chemistry

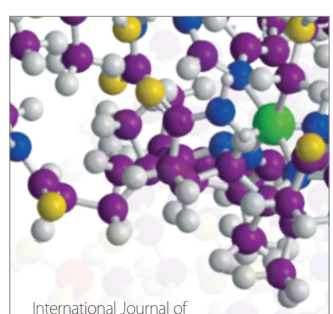

Carbohydrate Chemistry

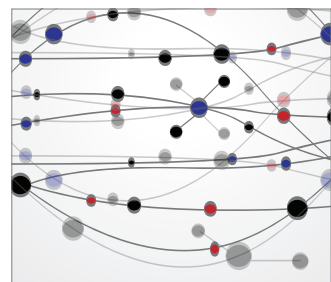

The Scientific World Journal
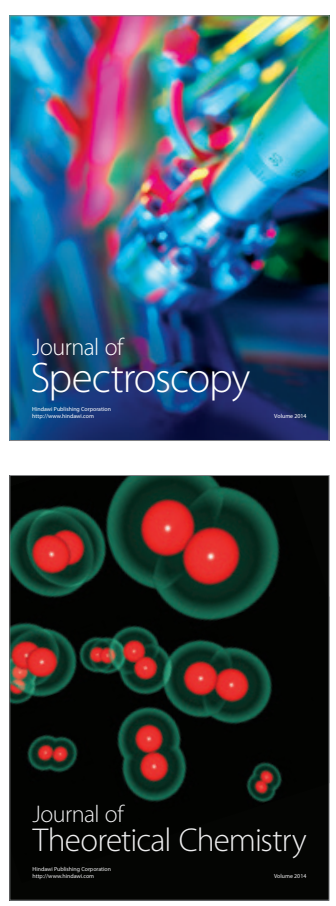
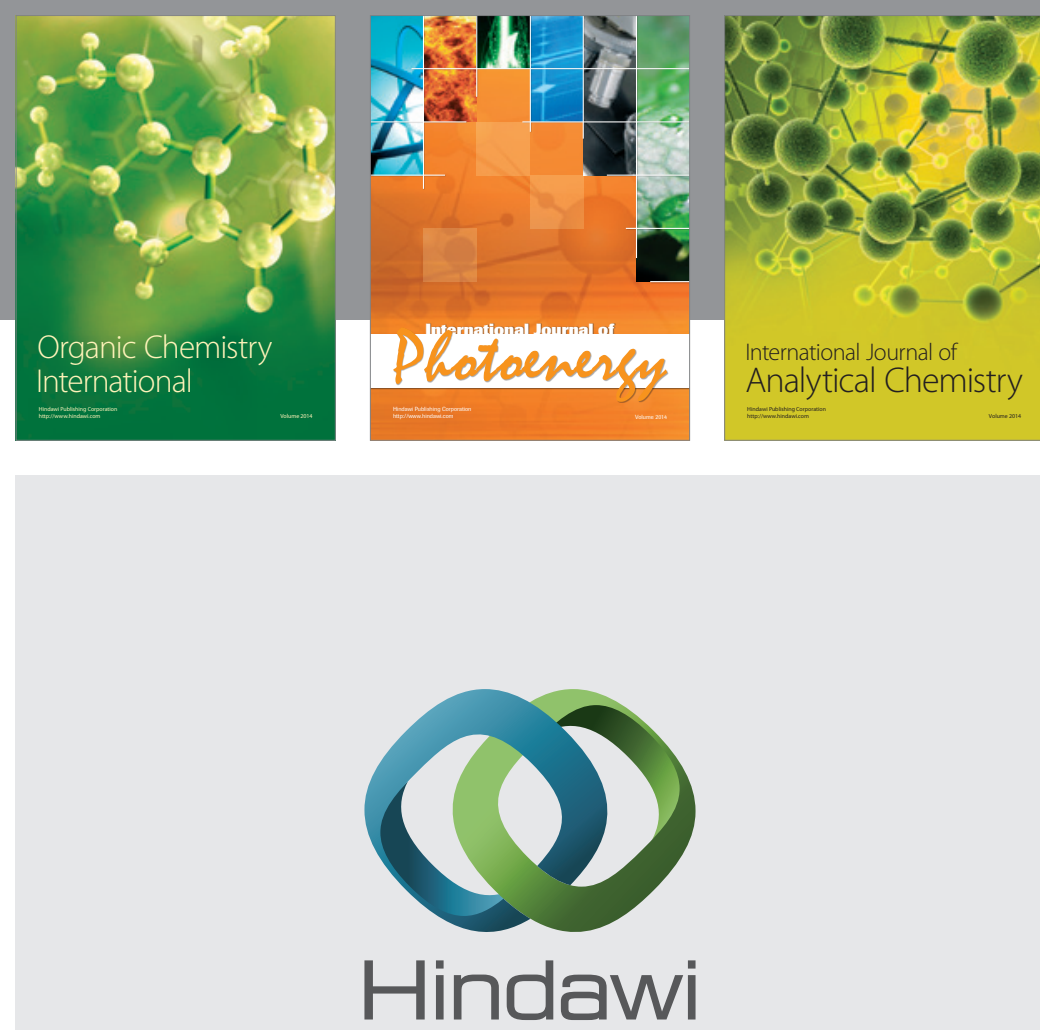

Submit your manuscripts at

http://www.hindawi.com
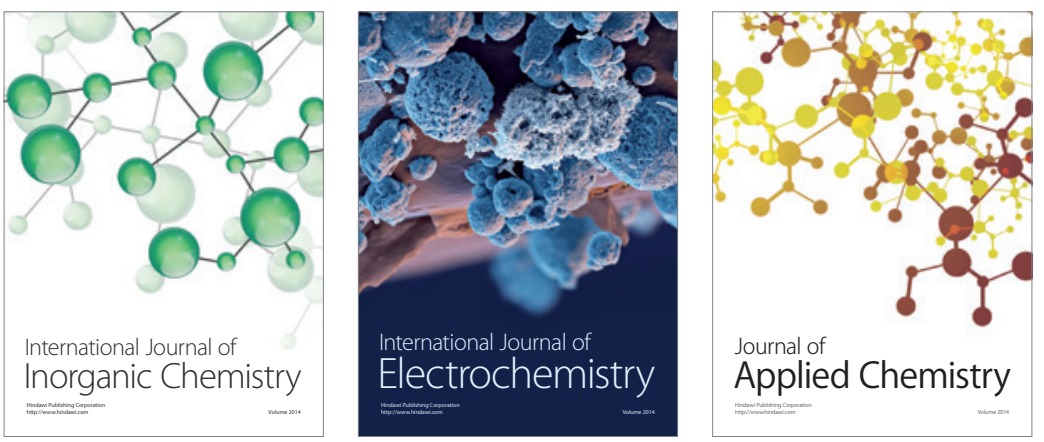

Journal of

Applied Chemistry
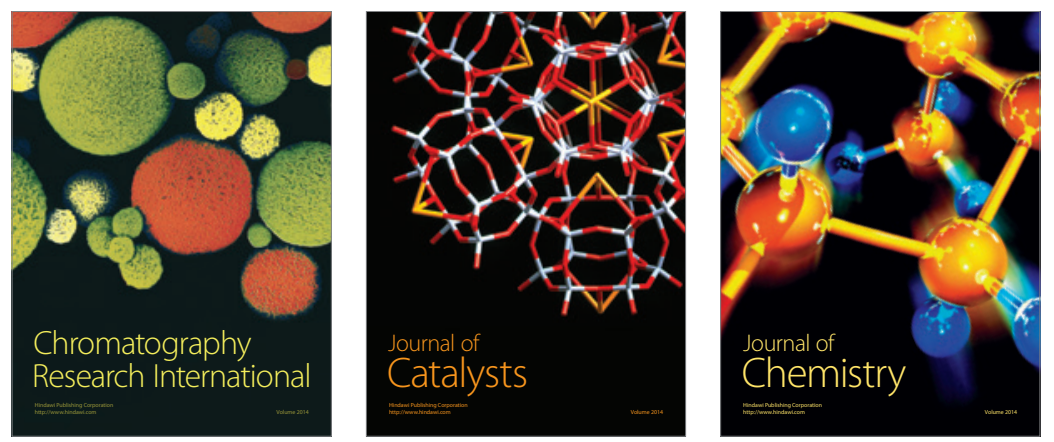
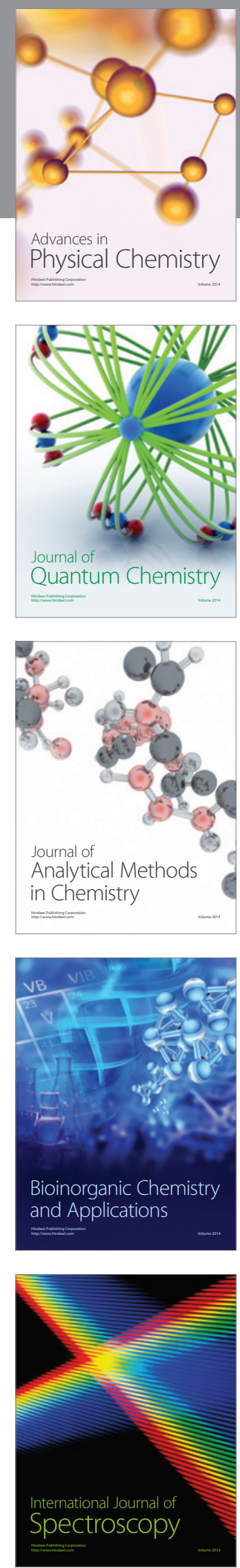